\title{
Prevalence and Influencing Factors of Anxiety and Depression Symptoms Amongst Surgical Nurses During COVID-19 Pandemic: A Large-Scale Cross- Sectional Study
}

\section{Chun-Xia Ren}

First Affiliated Hospital of Anhui Medical University

De-Cun Zhou

Anhui Medical College

Yin-Guang Fan

Anhui Medical University

Bao-Zhu Li

Anhui Medical University

Wan-Fei Zhang

Fujian Medical University Affiliated First Quanzhou Hospital

\section{Yun Shen}

First Affiliated Hospital of Anhui Medical University

Shi-Hui Yu

First Affiliated Hospital of Anhui Medical University

\section{Li Jiang}

Bozhou People's hospital

\section{Feng-Qiong Yu}

Anhui Medical University

\section{Yong-Li Duan}

Fuyang People's Hospital

\section{De-Qing Peng}

The People's Hospital of Xuancheng City

\section{Xue-Hong Cheng}

Anqing Hospital Affiliated Anhui Medical University

\section{Le Wu}

First Affiliated Hospital of Anhui Medical University

\section{Chang-Hao Wu}

University of Surrey

Dong-Qing Ye ( $\sim$ anhuiydq@126.com )

Anhui Medical University https://orcid.org/0000-0001-6604-9614 


\section{Research}

Keywords: surgical nurse, mental health, COVID-19, anxiety, depression, social support

Posted Date: December 11th, 2020

DOl: https://doi.org/10.21203/rs.3.rs-125116/v1

License: (c) (1) This work is licensed under a Creative Commons Attribution 4.0 International License. Read Full License 


\section{Abstract}

\section{Background}

The outbreak of novel 2019 coronavirus disease (COVID-19) has imposed an enormous physical and psychological pressure on people across the world. This study focused on evaluating the prevalence and influencing factors of anxiety and depression symptoms in surgical nurses during the epidemic in China.

Method

A cross-sectional, multicenter quantitative study was conducted in Anhui province (China) from March 3, 2020 to March 19, 2020, with a questionnaire package which consisted of general information questionnaire囚Zung's self-rating anxiety scale (SAS), Zung's self-rating Depression Scale (SDS) and social support rating scale (SSRS). A total of 3600 surgical nurses participated in the survey by Wechat and QQ. Data were analysed using multiple linear regression models.

Results

A total of 3492 surgical nurses from 12tertiary hospitals and 12 secondary hospitals in one province of mainland China completed the survey. The prevalence rates of anxiety symptoms and depressive symptoms were $24.83 \%$ and $22.39 \%$, respectively. The average level of anxiety and depression of surgical nurses were higher than that of the Chinese norm $(P<0.05)$.Levels of social support for surgical nurses were significantly negatively associated with the degree of anxiety $(r=-0.630, P<0.001)$ and depression $(r=-0.578, P<0.001)$. Fertility status $(\beta=1.469, P=0.003)$, hospital $(\beta=-0.611, P<0.001)$, participation in care for COVID-19 patients $(\beta=2.229, P<0.001)$, likelihood of being infected with COVID-19 $(\beta=1.146$, $P<0.001)$, social support $(\beta=-0.623, P<0.001)$ were significantly influencing surgical nurses' anxiety degree. Similarly, these characteristics were significantly associated with the odds of experiencing depression symptoms in surgical nurses. Divorce and widowed surgical nurses $(\beta=-2.654, P<0.001)$ were significantly more likely to experience depressive symptoms than single nurses.

Conclusion

In this survey, we found that the surgical nurses had high anxiety and depression symptoms during the COVID-19 outbreak in China. The findings suggest that targeted psychological interventions to promote the mental health of surgical nurses with psychological problems need to be immediately implemented.

\section{Introduction}

The outbreak of the coronavirus 2019 (COVID-19), formerly known as severe acute respiratory syndrome coronavirus 2 (SARS-CoV-2) [1], is continuously posing a serious public health threat worldwide. In response to COVID-19 pandemic, Nation Health Commission of China has placed COVID-19 under the statutory category B management of infectious diseases, and measures for class A infectious diseases should be taken for the prevention and control of COVID-19. Since January 2020, COVID-19 has spread 
rapidly in 211 countries and regions. Previous studies have shown that public health emergencies can easily cause anxiety and panic among healthcare workers, such as the severe acute respiratory syndrome [2]. Healthcare staff around the world are likely to be put in an unprecedented stressful situation by the COVID-19 pandemic [3], and nurses are no exception [4]. The COVID-19 pandemic presents significant challenges for healthcare workers, and impacts the entire health care system, with sustained strain on the system. In addition to the physical health, the potential psychological and mental health impacted by the COVID-19 pandemic should also be taken seriously. As this pandemic continues to exert a grave toll on the mental status of healthcare workers, there is an urgent need for health psychology research. Previous research has suggested that COVID-19 have psychological impacts on the frontline medical staff [5-6], administrative staff [7]. Moreover, a recent study warns that we should not neglect the mental health of the staff from other medical departments during the pandemic [8]. Wu et al found that in addition to the frontline healthcare workers, the working life of physicians and nurses is severely disrupted even in the usual hospital wards [9]. When dealing with challenges of the COVID-19 epidemic, surgical nurses are at increased risk of psychological health problems during the outbreak. Therefore, the psychological states of nurses working in the surgery department require our attention. The aim of our study was to examine the anxiety and depression levels of surgical nurses and to identify the risk factors for anxiety and depression in China during the COVID-19 epidemic. Our findings could help governments or health authorities to recognize the causes of increased anxiety in healthcare workers, and then to provide early effective measures to reduce that anxiety.

\section{Methods}

\section{Study design and participants}

A cross-sectional, correlational study was conducted among nurses employed in different surgical wards in Anhui province (China) from March 3, 2020 to March 19, 2020. Stratified cluster sampling method was used to recruit participants. Firstly, Anhui Province was divided into 3 parts as southern, central, and northern regions. Secondly, 2 cities were selected from each part with simple random sampling method. Then, 2 tertiary hospitals and 2 secondary hospitals were selected from each city. Finally, 200 surgical nurses in every tertiary hospital and 100 surgical nurses in every secondary hospital were enrolled as the participants. The inclusion criteria were as follows: 1) registered surgical nurses, 2) duration of the service over one year, 3) willing to be investigated. Exclusion criteria were as follows: 1) not in Anhui province, 2) with serious mental illness, such as schizophrenia or an intellectual disability; 3) without physical disease affecting anxiety or depression, such as hypothyroidism or coronary heart disease; 4) not on duty during the investigation period, such as maternity leave, sick leave. Socio-demographic characteristics and mental health measurements were collected by electronic questionnaires through Wechat. Ethical approval was issued by the Ethics Committee of the First Affiliated Hospital of Anhui Medical University (No. 2020R011).

\section{Survey methods}




\section{Sample size estimation}

It is estimated from the reference that the detection rate of anxiety in nurses is $20 \%$ [10]. Stratified cluster sampling method was used to recruit participants. The sample size calculation formula is as follows:

$$
\mathrm{N}=\quad \operatorname{deff} \frac{u^{2} p(1-p)}{\delta^{2}}
$$

$p=0.2 \rrbracket \delta=0.2 \times 15 \%=0.03 \rrbracket d e f f=1.5 \rrbracket a=0.05 \rrbracket u=1.96 \square$

After index insertion $\mathbb{N}=1024.42 \approx 1025$. Then Anhui province is divided into 3 layers according to geographical conditions $₫$ the total number is $1025 \times 3=3075$. Allowing for a $15 \%$ rejection rate, the total sample size is $3618 \otimes$ the integer is 3600 .

\section{Survey tools}

\section{(1) General Information Questionnaire}

By using the self-designed questionnaire, we have obtained the general demographic characteristics of the respondents, including age, gender, education level, character, marital status, fertility status, technical title, position, years registered as nurse, personnel relations, hospital, department, participation in care for COVID-19 patients, self-perceived likelihood of being infected COVID-19 (perception of being infected).

(2) Zung's self-rating anxiety scale (SAS)

The self-rating anxiety scale (SAS) [10] was used to assess anxiety symptoms of surgical nurses. The SAS includes 20 items, using a 4-point scale ranging from 1 (none, or a little of the time) to 4 (most, or all of the time), with total raw scores ranging from 20 to 80 [11]. Based on raw data multiplied by 1.25 , the standardized scores were classified into four categories, including normal (<49), mild anxiety (50-59), moderate anxiety (60-70) and severe anxiety $(>70)$.The index score of 50 is set as the morbidity cut-off. The SAS has been shown to have good internal consistency with a Cronbach's alpha of 0.82 [12]. Cronbach's a was 0.863 in the current study.

(3) Zung's self-rating Depression Scale (SDS)

The SDS was employed to assess the frequency of anxiety symptoms in surgical nurses. The SDS is a 20-item Likert and norm-referenced scale, the higher the score, the greater degree of depression [13]. Similar to SAS, the sum of the SDS raw scores was obtained on the 20 items by 80 , and converted to a whole number which ranges from 25 to 100 [12]. According to the Chinese norm [13], we also utilized the standard score of 53 as the critical value to divide depression in this study. An alpha coefficient of 0.81 was reported by Tanaka and Kameoka [12], while 0.792 was in our study.

(4) Social Support Rating Scale (SSRS) [14] 
The levels of social support for surgical nurses were evaluated by using the 14-item social support rate scale (SSRS). The SSRS was developed by Xiao Shuiyuan in 1986 and validated in a previous study. It contains three dimensions of objective support, subjective support, availability of support. The aggregate scores range from 12 to 66 , with higher scores indicating greater levels of perceived social support. Social support is categorized into three levels according to the total score, low ( $\leq 22)$, moderate (23-44), and high ( $\geq 45$ ). The Cronbach's alpha for internal consistency for the use of the SSRS was 0.808 [15]. The Cronbach's alpha of the SSRS was 0.796 in this sample.

\section{Procedures}

The Electronic "Questionnaire Star" Questionnaire (http://www.wjx.cn) was employed as the survey tool in the present study. The information on the participants was collected by WeChat. "Questionnaire Star" is a professional online survey platform, which can be used for questionnaire surveys, evaluation, voting, and other purposes [16]. After completing the questionnaire, participants' data were submitted electronically to a database that was read into a statistical software package (SPSS) for data analysis. Participants were informed that their responses would be kept confidential and that they were free to withdraw from the study at any time.

\section{Statistical analysis}

Data were analyzed using the statistical software package (SPSS) 20.0 (SPSS Institute Inc.). The data are presented using unadjusted means with standard deviations (SD) for continuous variables and unadjusted proportions for categorical variables. Comparison between groups was performed by $t$ test and one-way ANOVA. Pearson correlation analysis was used for correlation analysis. Linear regression models were used to evaluate the association between various factors and symptoms of anxieties and depression. A two-sided $p$ value $<0.05$ was considered statistically significant.

\section{Results}

\section{Participant characteristics}

Of 3600 invited surgical nurses in the Anhui surgical wards, 108 questionnaires were excluded for the irrational completion time (a dropout rate of $3.00 \%$ ) while data from 3492 subjects $(97.00 \%$ ) were eligible for the analysis. Their baseline characteristics are shown in Table 1. Socio-demographic characteristics and mental health measurements from the surgical nurses were obtained. Levels of anxiety, depression, and social support were measured using validated clinical questionnaires and scoring systems. The mean age (SD) was 32.3 (6.7) years and the largest age group was 30 40 years old. The majority of the sample was female (93.21\%) and married (73.25\%), had a bachelor's degree or above (67.99\%). Most participants had one child or more children (68.41\%). Among them, approximately half $(49.86 \%)$ had intermediate technical titles, and $1.66 \% \%$ had senior technical titles. Most subjects came from a clinical surgical department (87.03\%), $12.97 \%$ involved in administration. $95.25 \%$ of the participants perceived 
that they would be infected with COVID-19, and a total of 196 (5.61\%) surgical nurses directly treated the COVID-19 patients as shown in Table 1.

\section{Status of anxiety and depression in surgical nurses during COVID-19 pandemic}

To explore the psychological status of surgical nurses after the occurrence of COVID, we investigated the mean of anxiety and depression among these individuals using SAS and SDS questionnaires. Many participants experienced psychological symptoms, with $24.83 \%$ (867) and 782 (22.39\%) showing positive for anxiety and depression respectively (Table 2). Based on the scoring algorithm of SAS, the prevalence of anxiety was $24.83 \%$ (867/3492), with 663 respondents suffering from mild anxiety (18.99\%), 170 from moderate anxiety $(4.87 \%)$ and 34 from severe anxiety $(0.97 \%)$. According to SDS scoring method, the prevalence of depression was $22.39 \%$ (782/3492). A total of 603 respondents suffered from mild depression (17.26\%), 154 from moderate depression (4.41\%) and 25 nurses from severe depression (0.72\%) (Table 2).

As shown in Table 3, the prevalence of anxiety and depression symptoms was higher among surgical nurses during COVID-19 pandemic than the Chinese national norms $(P<0.001$ and $P<0.001$, respectively).

\section{Anxiety and depression status of surgical nurses with different demographic characteristics}

The associations between various factors and risk of anxiety are shown in Table 4. There is a significant difference between these two groups in terms of the variables of gender, age group, marital status, fertility status, technical title, working year $(P<0.05)$. Similarly, higher mean anxiety subscale scores were observed in surgical nurses in tertiary general hospitals $(P>0.05)$. The anxiety score was much higher as the self-perceived likelihood of being infected with COVID-19 increased $(P<0.05)$. The average anxiety score was significantly higher in surgical nurses who had directly treated COVID-19 cases, than the score in those who had not $(P<0.001)$. However, there were no statistical difference in anxiety scores with regards to the variables of gender, character, education, position, and personnel relation $(P>0.05)$.

Similar findings were made in the associations between different demographic characteristics and the anxiety level of the surgical nurses, as shown in Table 5.

\section{Correlation between anxiety, depression, and social support in surgical nurses during COVID-19 pandemic}

Pearson's correlation analysis revealed that the SAS and SDS scores had negative correlation with the SSRS total scores and the scores of its three dimensions, as shown in Table 6 and Table 7. There was a significant negative correlation between the SAS total scores and the SSRS total scores $(r=-0.630, P<$ $0.05)$, and a negative correlation between the SAS scores and the scores of subjective support $(r=-0.560$, $P<0.001)$, the scores of objective support $(\mathrm{r}=-0.495, P<0.001)$, and the scores for availability of support $(r=-0.405, P<0.001)$. Similarly, there was a negative association between the SDS total scores and the SSRS total scores $(r=-0.578, P<0.05)$, and a negative correlation between the SDS scores and the scores of three dimensions, $(P<0.001)$. Table 6 and Table 7 summarize these results. 


\section{Multiple-factor analysis on anxiety and depression of surgical nurses during COVID-19 pandemic}

Linear regression analysis revealed that having children, being in tertiary general hospitals, participation in care for COVID-19 patients, perception of being infected, and social support were the influencing factors for anxiety symptoms in surgical nurses $(P<0.05)$. However, there was no statistical significance between the association of anxiety symptom and age, technical title, working years $(P>0.05)$. Table 8 lists the results. The similar findings were shown in the Table 9 on the relationship between demographics, work related factors, and social support with depressive symptoms. Divorce/widowed was also associated with higher mean scores in the depression.

\section{Discussion}

\section{High positive rate of anxiety and depression symptoms amongst surgical nurses during COVID-19}

Although several studies reported that medical staff might suffer adverse psychological disorders, such as anxiety, fear and stigmatization, the psychological wellbeing of surgical nurses are little studied, and this should not be neglected. Importantly, surgical nurses encountering this situation are under extreme pressures. In the current cross-sectional study of 3492 surgical nurses, $24.83 \%$ and $22.39 \%$ of participants reported anxious and depressive symptoms, respectively, during the COVID-19 epidemic in Anhui province of China. Compared with the normal Chinese SAS and SDS score, the anxious and depressive levels of surgical nurses were relatively high.

Due to the special feature of surgical nursing care, COVID-19 epidemic may impact on the mental welling of surgical nurses. Firstly, COVID-19 causes many medical personnel to be easily infected in a short time when treating patients. Also surgical nurses play an important role in this pandemic; hence they face huge challenge and experience more stress. Secondly, in the initial period of COVID-19, not all patients undergoing emergency operation have been tested for viral nucleic acid, and it was impossible to determine whether the patient had a history of exposure to SARS-CoV-2. For those patients undergoing emergency operation, there was no time to test for viral nucleic acid. In addition, there were some confirmed SARS-CoV-2 cases that required surgical treatment. Moreover, surgical patients will not be reduced due to the outbreak of the epidemic. Consequently, these surgical nurses may have had a sense that the virus could impact on their workplace at any time, even though not always facing COVID-19 directly. Therefore, the surgical nurses had increased risk of infection, and would inevitably worry more about this risk, and the huge psychological pressure caused the anxiety and depression.

\section{Influencing factors of anxiety and depression in surgical nurses during COVID-19}

There were several factors that may have resulted in reduced mental wellbeing amongst surgical nurses during COVID-19. As shown in the results of this study, several risk factors have been found to influence poor wellbeing in surgical nurses following the outbreak. Those factors include having children, being in tertiary general hospitals, participation in care for COVID-19 patients, perception of being infected, and social support. In general, those surgical nurses having children, being in tertiary general hospitals, 
participating in care for COVID-19 patients, self-perception of being infected, and having lower level of social support, were more likely to have anxious and depressive symptoms during the COVID-19 epidemic.

\section{Having children and divorce/widowed}

As surgical nurses have been aware of the seriousness of the epidemic, they were afraid of passing the virus to their families, especially their own children. The majority of this sample were married, had children and usually played multiple roles of nurses, parents, spouses and children. These surgical nurses were under the pressure from both work and family, which could impose an additional emotional burden on them. Moreover, they did not want their families to worry about them. As a result, those nurses having children felt worse mental wellbeing during the COVID-19.

Since the surgical nurses in the single parent family take an important position in their families, while being lack of emotion support, suffering more difficulties, they could face more challenges in the crisis. Especially, they had the fear of exposing family members to COVID-19. In our study, the divorce or widowed nurses experienced more depression than the single and married nurses. If possible, at the COVID-19 outbreak, surgical nurses may be encouraged and supported to use alternative accommodations to reduce the risk of family transmission. Policy makers need to ensure they provide appropriate logistic and financial support to help with this course of action [17].

\section{Being in tertiary general hospitals}

In contrast to the surgical nurses in the secondary hospitals, those working in tertiary general hospitals may have perceived more anxiety and depression in our investigation. In general, the tertiary general hospitals were far more likely to treat the COVID-19 patients than the secondary hospitals. Additionally, the tertiary general hospitals treat more emergency and severe surgical patients who possibly have history of exposure to SARS-CoV-2. Therefore, surgical nurses in these hospitals could have high mean score of anxiety and depression during the COVID-19 pandemic.

\section{Participation in care for COVID-19 patients}

As the COVID-19 epidemic is a global issue, fighting COVID-19 appears to be a sustained task, which may result in surgical nurses suffering from psychological problems. During the outbreak of COVID-19, Chinese nurses, including surgical nurses have taken an active part in its prevention and treatment in the fever clinics, the observation wards and COVID-19 wards. Surgical nurses believed that people avoided them or their families due to their work with COVID-19 cases. Emerging evidence demonstrates that the frontline staff participating in treatments or procedures for infected COVID-19 cases experienced more stress, as they were at high potential risk of infection [18]. Therefore, surgical nurses having direct contact with COVID-19 patients suffered higher anxiety and depression scores than those who worked in the usual surgical departments. The risk-mitigating strategies [19], such as organizational implementation of 
infection control measures, avoidance of patients and complying with personal protective equipment can be adopted in the frontline work.

\section{Perception for likelihood of being infected with COVID-19}

Feeling unsafe and vulnerable to infection with COVID-19 was also closely related to the poor mental health in surgical nurses. Perceived threat or lack of safety has also been shown to be predictors of anxiety and depression symptoms. It should be noted that poor mental health may bias estimates of risk, and so the correlation between perceived risk and mental health symptoms may be bidirectional. Hence, treatment of the anxiety and depression symptoms themselves, or cognitive behavioral approaches designed to improve the psychological health of those with potential risk. Furthermore, precise and clear information about control measures may help reduce their anxiety and depression. The specialized training may minimize the amount of risk felt by surgical nurses and thus lead to more positive outcomes. Educational interventions aimed at addressing psychological distress and developing coping mechanisms to manage the fear of infection or infecting others should be developed and tested [20].

\section{Level of social support}

Our findings demonstrate that there was a negative association between anxiety/depression symptoms and social support. Great social support could be a protective factor against anxiety/depression, while those with poor perceived support were more likely to suffer from adverse outcomes. A recent study indicated that there was a negative correlation between the SSRS scores and the SAS scores, similar to our findings [21]. As family members or friends provide social and emotional support and share empathy [22], social support could help surgical nurses reduce anxiety and depression levels. Furthermore, social interactions are considered to reduce negative emotions such as anxiety and can improve the mood [23]. Adamczyk et al [24] suggested that having a wide social network could help reduce the perception of the threat of stressful events and the physiological response. Brooks suggested that social support from both employers and friends and families appeared to be useful for medical staff [20]. Therefore, building and encouraging the communications between surgical nurses and their families, employers, may relieve their psychological stress and strengthen the confidence in fighting COVID-19. Our findings support for the implementation of measures to improve the social support for surgical nurses during COVID-19 pandemic. In order to reduce feelings of social isolation in surgical nurses, Web-based communication, such as Wechat, QQ, microblog, are recommended to provide support during the crisis with no fear of transmission.

With surgical nurses as one of the medical forces to combat COVID-19, we must not ignore their psychological wellbeing while preventing and controlling the epidemic. As the pandemic is ongoing, important policy and clinical strategies are needed to support surgical nurses. To a certain extent, mental health problems will affect the performance of surgical nurses. Firstly, we need to identify and adjust the poor psychological status of surgical nurses, and promote the prevention and intervention of mental diseases. At the same time, professional psychotherapy teams should take the initiative to support their psychological health and provide individually targeted interventions. Secondly, healthcare managers 
should ensure there is regular adequate communication of up-to-date facts about the epidemic and how to best protect themselves. Meanwhile, managers should prepare their employees for the potential impact of negative experiences, such as anxiety and depression, and provide support measures for those. Lu et al [25] suggested that in the future advancement of a hospital in China, a human-oriented culture should be promoted to help the medical staff to deal with strain and reduce the risk of suffering from anxiety and depression. Regarding stress reduction, leisure activities and training on how to relax can be properly arranged. Moreover, hospital supporting staff can be organized better to reduce the pressure of ward administration for the surgical nurses. Recently, several UK researchers developed a digital package including evidence-based guidance, support and signposting relating to psychological wellbeing for healthcare workers. They recommend that this package be appropriate for supplementing strategic health and wellbeing provisions for healthcare workers during and after the COVID-19 pandemic [26]. Certainly, this e-package may be suitable for surgical nurses.

\section{Conclusions}

In conclusion, our study highlights that surgical nurses are at high risk of psychological distress during the COVID-19 outbreak. In a sample of 3492 surgical nurses, we found a sizable portion reached the cutoff levels of disorders in anxiety $(24.83 \%)$ and depression $(22.39 \%)$. Meanwhile, those who had children, worked in tertiary general hospitals, and treated COVID-19 patients directly, perceived themselves more likely to be infected with SARS-CoV-2, and those who had lower levels of social support were at a higher risk of developing anxious and depressive symptoms. These factors, together with the fear of being contagious and infecting others, could increase the possibility of psychological disorders among surgical nurses.

It is worth recommending that the formal psychological screening procedures be used for the surgical nurses either before the deployment or afterwards. In order to protect the mental health of medical nurses, early psychological interventions targeting this vulnerable group may be beneficial. It may be useful to have preparatory training packages and interventions to encourage medical nurses to focus on the potential positive impact of their work and coping strategies, which may help them to see the positive effects of working in a crisis. Possibly, pre-crisis training, and emphasizing the potential psychological impact of the outbreak are conducive to the mental health of surgical nurses. Moreover, healthcare organizations can make organizational supports congruent with nurses' specific needs, and help nurses reduce feelings of uncertainty and fear when these crises occur, to improve the quality of life.

Our study has several limitations. Firstly, our survey was conducted in March 2020, when COVID-19 was generally considered to be under control in China; our study has no way to ascertain the burnout mental status of surgical nurses at the onset or peak period of COVID-19 crisis. Also we were unable to distinguish pre-existing anxiety from new cases of anxiety and depression. In fact, COVID-19-related anxiety is likely to be dynamic, waxing and waning in response to stressors. In our study, however, we were unable to explore anxiety and depression in surgical nurses at different stages. Future research should be aimed at collecting more comprehensive data on the mental wellbeing of surgical nurses in the 
COVID-19 crisis. Due to ethical requirements on anonymity and confidentiality, we were not allowed to collect contact details and personal information from the respondents. As a result, we could not conduct a prospective study that would provide a concrete finding to support the need for a focused public health initiative. Secondly, our study explored a cross-sectional design that can only suggest associations rather than causality. Prospective, longitudinal studies and randomized controlled trials are needed to adequately explore risk factors. Thirdly, the present study was performed only in one province of China, which may limit the generalizability of the findings. Hence, caution should be taken in generalizing the results to all medical staff in China. Follow-up studies could help assess the progression or even a potential rebound effect of psychological manifestations once the imminent threat of COVID-19 subsides. Finally, subjective self-reported questionnaires were used to obtain the data in this study. Future studies may employ the objective indicators of anxiety and depression, such as serum cortisol level.

Our study also has several strengths. To our knowledge, this is the first study to assess anxiety and depression levels among surgical nurses in China during the COVID-19 period, and the comprehensive statistical data analyses were used to ensure results reliable. In addition, our findings may encourage policy-makers and governments to consider offering early interventions to alleviate possible mental health problems in surgical nurses.

\section{Abbreviations}

COVID-19: coronavirus 2019; SAS: Zung's self-rating anxiety scale; SDS: Zung's self-rating Depression Scale; SSRS: Social Support Rating Scale; SPSS: statistical software package; SD: standard deviations

\section{Declarations}

\section{Acknowledgements}

The authors would like to acknowledge all the surgical nurses participated in this study and the Center of Medical Humanities, Anhui Medical University for providing support for our study.

\section{Authors' contributions}

CXR and CHW and DQY contributed to the conceptualization and design of the study. DCZ and BZL and YS and SHY and LJ and FQY and YLD and DQP and XHC and LW conducted the survey while CXR and YGF and WFZ conducted data analysis.CXR wrote the first draft, which underwent substantial revision based on the inputs from all other authors. DCZ supervised the whole study process. All the authors have read and approved the final version of the manuscript.

\section{Funding}

This study was supported by the COVID-19 Prevention and Control Rapid Response Grant (grant number: YJSK202014), Center of Medical Humanities, Anhui Medical University. 
Availability of data and materials

All data generated during the study are included in the manuscript and the supplementary file.

\section{Ethics approval and consent to participate}

Ethical approval for this study was issued by the Ethics Committee of the First Affiliated Hospital of Anhui Medical University (No. 2020R011). The participants were informed clearly about their freedom to withdraw from the study without any reason at any time.

\section{Consent for publication}

Not applicable.

\section{Competing Interests}

The authors declare that they have no known competing financial interests or personal relationships that could have appeared to influence the work reported in this paper.

\section{References}

1. Zheng J. SARS-CoV-2: an Emerging Coronavirus that Causes a Global Threat. Int J Biol Sci. 2020;16(10):1678-1685.

2. Chong MY, Wang WC, Hsieh WC, Lee CY, Chiu NM, Yeh WC, Huang OL, Wen JK, Chen CL.

Psychological impact of severe acute respiratory syndrome on health workers in a tertiary hospital. Br J Psychiatry. 2004;185:127-133.

3. Chew NWS, Lee GKH, Tan BYQ, Jing M, Goh Y, Ngiam NJH, Yeo LLL, Ahmad A, Ahmed Khan F, Napolean Shanmugam G, Sharma AK, Komalkumar RN, Meenakshi PV, Shah K, Patel B, Chan BPL, Sunny S, Chandra B, Ong JJY, Paliwal PR, Wong LYH, Sagayanathan R, Chen JT, Ying Ng AY, Teoh HL, Tsivgoulis G, Ho CS, Ho RC, Sharma VK. A multinational, multicentre study on the psychological outcomes and associated physical symptoms amongst healthcare workers during COVID-19 outbreak. Brain Behav Immun. 2020;88:559-565.

4. Stelnicki AM, Carleton RN, Reichert C. Nurses' Mental Health and Well-Being: COVID-19 Impacts. Can J Nurs Res. 2020;52(3):237-239.

5. Kang L, Ma S, Chen M, Yang J, Wang Y, Li R, Yao L, Bai H, Cai Z, Xiang Yang B, Hu S, Zhang K, Wang G, Ma C, Liu Z. Impact on mental health and perceptions of psychological care among medical and nursing staff in Wuhan during the 2019 novel coronavirus disease outbreak: A cross-sectional study. Brain Behav Immun. 2020;87:11-17.

6. Song X, Fu W, Liu X, Luo Z, Wang R, Zhou N, Yan S, Lv C. Mental health status of medical staff in emergency departments during the Coronavirus disease 2019 epidemic in China. Brain Behav Immun. 2020;88:60-65. 
7. Luo LS, Jin YH, Cai L, Pan ZY, Zeng XT, Wang XH. COVID-19: Presumed Infection Routes and Psychological Impact on Staff in Administrative and Logistics Departments in a Designated Hospital in Wuhan, China. Front Psychol. 2020;11:1501.

8. Liang Y, Chen M, Zheng X, Liu J. Screening for Chinese medical staff mental health by SDS and SAS during the outbreak of COVID-19. J Psychosom Res. 2020;133:110102.

9. Wu Y, Wang J, Luo C, Hu S, Lin X, Anderson AE, Bruera E, Yang X, Wei S, Qian Y. A Comparison of Burnout Frequency Among Oncology Physicians and Nurses Working on the Frontline and Usual Wards During the COVID-19 Epidemic in Wuhan, China. J Pain Symptom Manage. 2020;60(1):e60e65.

10. Zung WW. A rating instrument for anxiety disorders. Psychosomatics. 1971;12(6):371-

11. Zung WW. The measurement of affects: depression and anxiety. Mod Probl Pharmacopsychiatry. $1974 ; 7(0): 170-88$.

12. Tanaka-Matsumi J, Kameoka VA. Reliabilities and concurrent validities of popular self-report measures of depression, anxiety, and social desirability. J Consult Clin Psychol. 1986;54(3):328-333.

13. Zung WW. A Self-Rating Depression Scale. Arch Gen Psychiatry, 1965;12:63-

14. Xu J, Chen P, Ma X. The relationship among preconception depression, anxiety, and social support of the reproductive-aged women in China. Arch Womens Ment Health. 2018;21(4):429-436.

15. Zhang W, Xu H, Zhao S, Yin S, Wang X, Guo J, Zhang S, Zhou H, Wang F, Gu L, Zhu L, Yu H, Qu Z, Tian D. Prevalence and influencing factors of co-morbid depression in patients with type 2 diabetes mellitus: a General Hospital based study. Diabetol Metab Syndr. 2015;7:60.

16. Huang L, Lei W, Xu F, Liu H, Yu L. Emotional responses and coping strategies in nurses and nursing students during Covid-19 outbreak: A comparative study. PLoS One. 2020;15(8):e0237303.

17. Bagnasco A, Zanini M, Hayter M, Catania G, Sasso L. COVID 19-A message from Italy to the global nursing community. J AdvNurs. 2020;76(9):2212-2214.

18. Liu CY, Yang YZ, Zhang XM, Xu X, Dou QL, Zhang WW, Cheng ASK. The prevalence and influencing factors in anxiety in medical workers fighting COVID-19 in China: a cross-sectional survey. Epidemiol Infect. 2020;148:e98.

19. Koh Y, Hegney DG, Drury V. Comprehensive systematic review of healthcare workers' perceptions of risk and use of coping strategies towards emerging respiratory infectious diseases. Int J Evid Based Healthc. 2011;9(4):403-419.

20. Brooks SK, Dunn R, Amlôt R, Rubin GJ, Greenberg N. A Systematic, Thematic Review of Social and Occupational Factors Associated With Psychological Outcomes in Healthcare Employees During an Infectious Disease Outbreak. J Occup Environ Med. 2018;60(3):248-257.

21. Xiao H, Zhang Y, Kong D, Li S, Yang N. The Effects of Social Support on Sleep Quality of Medical Staff Treating Patients with Coronavirus Disease 2019 (COVID-19) in January and February 2020 in China. Med SciMonit. 2020;26:e923549. 
22. Yang N, Xiao H, Wang W, Li S, Yan H, Wang Y. Effects of doctors' empathy abilities on the cellular immunity of patients with advanced prostate cancer treated by orchiectomy: the mediating role of patients' stigma, self-efficacy, and anxiety. Patient Prefer Adherence. 2018;12:1305-1314.

23. Yang N, Xiao H, Cao Y, Li S, Yan H, Wang Y. Influence of oncology nurses' empathy on lung cancer patients' cellular immunity. Psychol Res Behav Manag. 2018;11:279-287.

24. Adamczyk K, Segrin C. Perceived social support and mental health among single partnered polish young adults. Curr Psychol. 2015;34: 82-96

25. Lu W, Wang H, Lin Y, Li L. Psychological status of medical workforce during the COVID-19 pandemic: A cross-sectional study. Psychiatry Res. 2020;288:112936.

26. Blake H, Bermingham F, Johnson G, Tabner A. Mitigating the Psychological Impact of COVID-19 on Healthcare Workers: A Digital Learning Package. Int J Environ Res Public Health. 2020;17(9):2997.

\section{Tables}

\section{Table 1 Participant Characteristics at Baseline (n, \%)}




\begin{tabular}{|c|c|c|c|}
\hline Variables & & Number & $\begin{array}{l}\text { Percentage } \\
\square \% \square\end{array}$ \\
\hline \multirow[t]{2}{*}{ Gender } & Male & 237 & 6.79 \\
\hline & Female & 3255 & 93.21 \\
\hline \multirow[t]{3}{*}{ Age } & $\bowtie 30$ years & 1337 & 38.29 \\
\hline & 30 40years & 1745 & 49.97 \\
\hline & \40years & 410 & 11.74 \\
\hline \multirow[t]{4}{*}{ character } & Introversion & 785 & 22.48 \\
\hline & Extroversion & 659 & 18.87 \\
\hline & Mixed personality & 1833 & 52.49 \\
\hline & uncertainty & 215 & 6.16 \\
\hline \multirow[t]{4}{*}{ Educational level } & Technical school & 69 & 1.98 \\
\hline & College & 1049 & 30.04 \\
\hline & University & 2358 & 67.53 \\
\hline & Graduate school & 16 & 0.46 \\
\hline \multirow[t]{3}{*}{ Marital status } & Single & 865 & 24.77 \\
\hline & Married & 2558 & 73.25 \\
\hline & Divorce/Widowed & 69 & 1.98 \\
\hline \multirow[t]{2}{*}{ Fertility status } & One or more children & 2389 & 68.41 \\
\hline & No child & 1103 & 31.59 \\
\hline \multirow[t]{4}{*}{ Technical title } & None & 440 & 12.60 \\
\hline & Junior & 1253 & 35.88 \\
\hline & Intermediate & 1741 & 49.86 \\
\hline & Senior & 58 & 1.66 \\
\hline \multirow[t]{3}{*}{ Position } & Nurse & 3039 & 87.03 \\
\hline & Head nurse & 399 & 11.43 \\
\hline & $\begin{array}{l}\text { Department head nurse or } \\
\text { more }\end{array}$ & 54 & 1.54 \\
\hline \multirow[t]{2}{*}{ Years registered as nurse } & 1 2year & 362 & 10.37 \\
\hline & 3 5year & 631 & 18.07 \\
\hline
\end{tabular}




\begin{tabular}{|c|c|c|c|}
\hline & 6 10year & 1122 & 32.13 \\
\hline & ه10year & 1377 & 39.43 \\
\hline \multirow[t]{3}{*}{ Personnel relations } & Formal establishment & 765 & 21.91 \\
\hline & Personnel agency & 1024 & 29.32 \\
\hline & Engaging system & 1703 & 48.77 \\
\hline \multirow[t]{4}{*}{ Hospital } & Tertiary general hospitals & 1917 & 54.90 \\
\hline & Tertiary specialized hospitals & 104 & 2.98 \\
\hline & Secondary general hospitals & 1413 & 40.46 \\
\hline & $\begin{array}{l}\text { Secondary specialized } \\
\text { hospitals }\end{array}$ & 58 & 1.66 \\
\hline \multirow[t]{6}{*}{ Department } & General surgery department & 1037 & 29.7 \\
\hline & Urinary surgery & 553 & 15.8 \\
\hline & Orthopedics department & 500 & 14.3 \\
\hline & Neurosurgery department & 459 & 13.1 \\
\hline & $\begin{array}{l}\text { Cardiothoracic surgery } \\
\text { department }\end{array}$ & 400 & 11.5 \\
\hline & Orthopaedic burn surgery & 137 & 3.9 \\
\hline \multirow{2}{*}{$\begin{array}{l}\text { Participation in care for COVID-19 } \\
\text { patients }\end{array}$} & Yes & 196 & 5.61 \\
\hline & No & 3296 & 94.39 \\
\hline \multirow{3}{*}{$\begin{array}{l}\text { Self-perception for being infected with } \\
\text { COVID- } 19\end{array}$} & None & 166 & 4.75 \\
\hline & Mild & 1992 & 57.04 \\
\hline & Moderate & 973 & 27.86 \\
\hline Perception of being infected & Severe & 361 & 10.34 \\
\hline
\end{tabular}

Table 2 Prevalence of depression and anxiety in surgical nurses $(N=3492)$

\begin{tabular}{|c|c|c|c|c|}
\hline Variables & non & mild & moderate & severe \\
\hline Anxiety & $2625 \rrbracket 75.17 \% \rrbracket$ & $663 \rrbracket 18.99 \% \rrbracket$ & $170 ه 4.87 \% \rrbracket$ & $34 \rrbracket 0.97 \% \rrbracket$ \\
\hline Depression & $2710 \rrbracket 77.61 \% \rrbracket$ & $603 \rrbracket 17.26 \% \rrbracket$ & $154 \rrbracket 4.41 \% \rrbracket$ & $25 \bowtie 0.72 \% \rrbracket$ \\
\hline
\end{tabular}

Table 3 Comparison of the average level of anxiety and depression between surgical nurses and the Chinese norms during COVID epidemic (score \pm ts) 


\begin{tabular}{|lllll|}
\hline Variables & Surgical nurses & Chinese norm & $t$-value & $P$-value \\
\hline SAS score & $43.32 \pm 9.01$ & $37.23 \pm 12.59$ & 39.981 & $<0.001$ \\
\hline SDS score & $45.09 \pm 9.61$ & $41.88 \pm 10.57$ & 19.764 & $<0.001$ \\
\hline
\end{tabular}

Table 4 Comparison of anxiety status among surgical nurses with different demographic characteristics (score, $\pm s$ ) 


\begin{tabular}{|c|c|c|c|c|c|}
\hline Subgroups & & $\mathrm{n}$ & $\begin{array}{l}\text { Anxiety } \\
\text { scores }\end{array}$ & $\begin{array}{l}\mathrm{F} / \mathrm{t} \\
\text { value }\end{array}$ & $\begin{array}{l}P \text { - } \\
\text { value }\end{array}$ \\
\hline \multirow[t]{2}{*}{ Gender } & Male & 237 & $43.58 \pm 8.85$ & & \\
\hline & Female & 3255 & $43.31 \pm 9.02$ & 0.450 & 0.653 \\
\hline \multirow[t]{3}{*}{ Age } & \30years & 1337 & $42.39 \pm 8.82$ & & \\
\hline & 30 40years & 1745 & $44.14 \pm 8.92$ & & \\
\hline & \40years & 410 & $42.91 \pm 9.68$ & 14.968 & $\begin{array}{l}\square \\
0.001\end{array}$ \\
\hline \multirow[t]{4}{*}{ character } & Introversion & 785 & $43.83 \pm 9.51$ & & \\
\hline & Extroversion & 659 & $43.73 \pm 9.39$ & & \\
\hline & Mixed personality & 1833 & $42.97 \pm 8.57$ & & \\
\hline & Uncertainty & 215 & $43.30 \pm 9.44$ & 2.235 & 0.082 \\
\hline \multirow[t]{3}{*}{ Educational level } & Technical school & 69 & $44.81 \pm 8.39$ & & \\
\hline & College & 1049 & $43.22 \pm 9.27$ & & \\
\hline & University and over & 2374 & $43.32 \pm 8.91$ & 1.006 & 0.366 \\
\hline \multirow[t]{3}{*}{ Marital status } & Single & 865 & $41.82 \pm 8.74$ & & \\
\hline & Married & 2558 & $43.69 \pm 9.00$ & & \\
\hline & Dicorce/Widowed & 69 & $48.75 \pm 9.27$ & 27.114 & 0.001 \\
\hline \multirow[t]{2}{*}{ Fertility status } & One or more children & 2389 & $44.05 \pm 9.13$ & & \\
\hline & No child & 1103 & $41.76 \pm 8.53$ & 7.216 & $\begin{array}{l}\square \\
0.001\end{array}$ \\
\hline \multirow[t]{4}{*}{ Technical title } & None & 440 & $42.17 \pm 8.60$ & & \\
\hline & Junior & 1253 & $43.10 \pm 9.15$ & & \\
\hline & Intermediate & 1741 & $43.75 \pm 9.01$ & & \\
\hline & Senior & 58 & $44.10 \pm 8.22$ & 4.131 & 0.006 \\
\hline \multirow[t]{3}{*}{ Position } & Nurse & 3039 & $43.33 \pm 9.01$ & & \\
\hline & Head nurse & 399 & $43.19 \pm 9.08$ & & \\
\hline & $\begin{array}{l}\text { Department head } \\
\text { nurse or more }\end{array}$ & 54 & $44.00 \pm 8.48$ & 0.196 & 0.822 \\
\hline \multirow[t]{2}{*}{ Years registered as nurse } & 1 2year & 362 & $42.00 \pm 8.64$ & & \\
\hline & 3 5year & 631 & $42.07 \pm 8.59$ & & \\
\hline
\end{tabular}

Page 19/25 


\begin{tabular}{|c|c|c|c|c|c|}
\hline & 6 10year & 1122 & $43.90 \pm 9.20$ & & \\
\hline & \10year & 1377 & $43.77 \pm 9.05$ & 9.419 & $\begin{array}{l}\square \\
0.001\end{array}$ \\
\hline \multirow[t]{3}{*}{ Personnel relations } & Formal establishment & 765 & $43.14 \pm 8.99$ & & \\
\hline & Personnel agency & 1024 & $43.10 \pm 8.61$ & & \\
\hline & Engaging system & 1703 & $43.54 \pm 9.25$ & 0.983 & 0.374 \\
\hline \multirow[t]{4}{*}{ Hospital } & $\begin{array}{l}\text { Tertiary general } \\
\text { hospitals }\end{array}$ & 1917 & $44.11 \pm 9.21$ & & \\
\hline & $\begin{array}{l}\text { Tertiary specialized } \\
\text { hospitals }\end{array}$ & 104 & $41.30 \pm 6.80$ & & \\
\hline & $\begin{array}{l}\text { Secondary general } \\
\text { hospitals }\end{array}$ & 1413 & $42.55 \pm 8.79$ & & \\
\hline & $\begin{array}{l}\text { Secondary specialized } \\
\text { hospitals }\end{array}$ & 58 & $39.83 \pm 7.97$ & 13.215 & $\begin{array}{l}\square \\
0.001\end{array}$ \\
\hline \multirow{3}{*}{$\begin{array}{l}\text { Participation in care for } \\
\text { COVID-19 patients }\end{array}$} & Yes & 196 & $48.73 \pm 11.02$ & & \\
\hline & No & 3296 & $43.00 \pm 8.77$ & 8.750 & 0.001 \\
\hline & None & 166 & $40.69 \pm 9.89$ & & \\
\hline \multirow{3}{*}{$\begin{array}{l}\text { Self-perception for being } \\
\text { infected with COVID- } 19\end{array}$} & Mild & 1992 & $40.87 \pm 7.42$ & & \\
\hline & Moderate & 973 & $46.56 \pm 8.83$ & & \\
\hline & Severe & 361 & $49.37 \pm 11.19$ & 172.149 & $\begin{array}{l}\square \\
0.001\end{array}$ \\
\hline
\end{tabular}

Table 5 Comparison of depression status among surgical nurses with different demographic characteristics (score, $\pm s$ ) 


\begin{tabular}{|c|c|c|c|c|c|}
\hline Subgroups & & $\mathrm{n}$ & $\begin{array}{l}\text { Depression } \\
\text { scores }\end{array}$ & $\begin{array}{l}\mathrm{F} / \mathrm{t} \\
\text { value }\end{array}$ & $\begin{array}{l}P \text { - } \\
\text { value }\end{array}$ \\
\hline \multirow[t]{2}{*}{ Gender } & Male & 237 & $46.17 \pm 9.82$ & & \\
\hline & Female & 3255 & $45.02 \pm 9.59$ & 1.783 & 0.075 \\
\hline \multirow[t]{3}{*}{ Age } & §30years & 1337 & $43.31 \pm 9.41$ & & \\
\hline & 30 40years & 1745 & $45.60 \pm 9.69$ & & \\
\hline & $₫ 40$ years & 410 & $45.50 \pm 9.76$ & 7.325 & 0.001 \\
\hline \multirow[t]{4}{*}{ character } & Introversion & 785 & $45.54 \pm 10.15$ & & \\
\hline & Extroversion & 659 & $45.54 \pm 9.42$ & & \\
\hline & Mixed personality & 1833 & $44.77 \pm 9.33$ & & \\
\hline & uncertainty & 215 & $44.87 \pm 10.45$ & 1.785 & 0.148 \\
\hline \multirow[t]{3}{*}{ Educational level } & Technical school & 69 & $46.96 \pm 8.58$ & & \\
\hline & College & 1049 & $45.24 \pm 9.77$ & & \\
\hline & University and over & 2374 & $44.98 \pm 9.57$ & 1.585 & 0.205 \\
\hline \multirow[t]{3}{*}{ Marital status } & Single & 865 & $43.39 \pm 9.26$ & & \\
\hline & Married & 2558 & $45.63 \pm 9.68$ & & \\
\hline & Divorce/Widowed & 69 & $46.62 \pm 8.94$ & 18.635 & 0.001 \\
\hline \multirow[t]{2}{*}{ Fertility status } & One or more children & 2389 & $45.90 \pm 9.77$ & & \\
\hline & No child & 1103 & $43.36 \pm 9.03$ & 7.522 & 0.001 \\
\hline \multirow[t]{4}{*}{ Technical title } & None & 440 & $43.98 \pm 9.47$ & & \\
\hline & Junior & 1253 & $44.68 \pm 9.52$ & & \\
\hline & Intermediate & 1741 & $45.64 \pm 9.68$ & & \\
\hline & Senior & 58 & $46.24 \pm 9.63$ & 4.906 & 0.002 \\
\hline \multirow[t]{3}{*}{ Position } & Nurse & 3039 & $45.08 \pm 9.58$ & & \\
\hline & Head nurse & 399 & $45.01 \pm 9.77$ & & \\
\hline & $\begin{array}{l}\text { Department head } \\
\text { nurse or more }\end{array}$ & 54 & $46.59 \pm 10.44$ & 0.677 & 0.508 \\
\hline \multirow[t]{2}{*}{ Years registered as nurse } & 1 2year & 362 & $43.90 \pm 9.54$ & & \\
\hline & 3 5year & 631 & $43.60 \pm 9.06$ & & \\
\hline
\end{tabular}




\begin{tabular}{|c|c|c|c|c|c|}
\hline & 6 10year & 1122 & $45.57 \pm 9.65$ & & \\
\hline & \10year & 1377 & $45.70 \pm 9.75$ & 9.815 & $\begin{array}{l}\square \\
0.001\end{array}$ \\
\hline \multirow[t]{3}{*}{ Personnel relations } & Formal establishment & 765 & $45.02 \pm 9.91$ & & \\
\hline & Personnel agency & 1024 & $44.69 \pm 9.09$ & & \\
\hline & Engaging system & 1703 & $45.37 \pm 9.77$ & 1.615 & 0.199 \\
\hline \multirow[t]{4}{*}{ Hospital } & $\begin{array}{l}\text { Tertiary general } \\
\text { hospitals }\end{array}$ & 1917 & $45.97 \pm 9.72$ & & \\
\hline & $\begin{array}{l}\text { Tertiary specialized } \\
\text { hospitals }\end{array}$ & 104 & $43.87 \pm 7.66$ & & \\
\hline & $\begin{array}{l}\text { Secondary general } \\
\text { hospitals }\end{array}$ & 1413 & $44.19 \pm 9.49$ & & \\
\hline & $\begin{array}{l}\text { Secondary } \\
\text { specialized hospitals }\end{array}$ & 58 & $40.36 \pm 8.61$ & 14.976 & $\begin{array}{l}\square \\
0.001\end{array}$ \\
\hline \multirow{2}{*}{$\begin{array}{l}\text { Participation in care for } \\
\text { COVID-19 patients }\end{array}$} & Yes & 196 & $51.68 \pm 12.11$ & & \\
\hline & No & 3296 & $44.70 \pm 9.30$ & 7.933 & $\begin{array}{l}\square \\
0.001\end{array}$ \\
\hline \multirow{4}{*}{$\begin{array}{l}\text { Self-perception for being } \\
\text { infected with COVID-19 }\end{array}$} & None & 166 & $42.41 \pm 10.53$ & & \\
\hline & Mild & 2012 & $42.51 \pm 7.65$ & & \\
\hline & Moderate & 973 & $48.39 \pm 9.95$ & & \\
\hline & Severe & 341 & $51.68 \pm 11.89$ & 167.813 & $\begin{array}{l}\square \\
0.001\end{array}$ \\
\hline
\end{tabular}

Table 6 The relationships between SAS scores and SSRS scoresof surgical nurses during COVID-19 pandemic $(N=3492)$ 


\begin{tabular}{|c|c|c|c|c|c|c|}
\hline \multirow[t]{3}{*}{ Variables } & \multirow{3}{*}{$\begin{array}{l}\text { Score } \\
\text { scope }\end{array}$} & \multirow[t]{3}{*}{$\square \pm s \square$} & \multicolumn{2}{|l|}{ Anxiety $\square \pm s \square$} & \multirow{3}{*}{$\begin{array}{l}F \\
\text { value }\end{array}$} & \multirow{3}{*}{$\begin{array}{l}P \text { - } \\
\text { value }\end{array}$} \\
\hline & & & None & Anxiety & & \\
\hline & & & 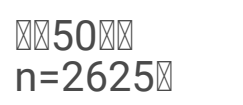 & $\begin{array}{l}\bigotimes \geq 50 \otimes \square \\
n=867 \rrbracket\end{array}$ & & \\
\hline Subject support & $8 \sim 32$ & $21.36 \pm 4.65$ & $22.68 \pm 4.13$ & $17.37 \pm 3.79$ & -0.560 & $\begin{array}{l}\square \\
0.001\end{array}$ \\
\hline Objective support & $1 \sim 22$ & $10.84 \pm 3.76$ & $11.73 \pm 3.60$ & $8.15 \pm 2.87$ & -0.495 & $\begin{array}{l}\square \\
0.001\end{array}$ \\
\hline $\begin{array}{l}\text { Availability of } \\
\text { support }\end{array}$ & $3 \sim 12$ & $8.42 \pm 1.92$ & $8.81 \pm 1.81$ & $7.25 \pm 1.79$ & -0.405 & $\begin{array}{l}0.001 \\
\square\end{array}$ \\
\hline Total score & $12 \sim 66$ & $40.62 \pm 8.33$ & $43.22 \pm 7.16$ & $32.77 \pm 6.48$ & -0.630 & $\begin{array}{l}\square \\
0.001\end{array}$ \\
\hline
\end{tabular}

Table 7 The relationships between SDS scores and SSRS scores of surgical nurses during COVID-19 pandemic $(N=3492)$

\begin{tabular}{|c|c|c|c|c|c|c|}
\hline \multirow[t]{3}{*}{ Variables } & \multirow{3}{*}{$\begin{array}{l}\text { Score } \\
\text { scope }\end{array}$} & \multirow[t]{3}{*}{$\square \pm s \square$} & \multicolumn{2}{|c|}{ Depression $\square \pm s \square$} & \multirow{3}{*}{$\begin{array}{l}r- \\
\text { value }\end{array}$} & \multirow{3}{*}{$\begin{array}{l}P- \\
\text { value }\end{array}$} \\
\hline & & & None & Depression & & \\
\hline & & & 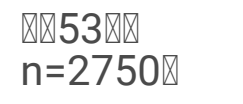 & $\begin{array}{l}\bigotimes \geq 53 \triangle \square \\
n=742 \rrbracket\end{array}$ & & \\
\hline Subject support & $8 \sim 32$ & $21.36 \pm 4.65$ & $22.44 \pm 4.23$ & $17.62 \pm 4.07$ & -0.514 & $\begin{array}{l}\square \\
0.001\end{array}$ \\
\hline Objective support & $1 \sim 22$ & $10.84 \pm 3.76$ & $11.56 \pm 3.65$ & $8.34 \pm 3.02$ & -0.449 & $\begin{array}{l}0.001 \\
0.00\end{array}$ \\
\hline $\begin{array}{l}\text { Availability of } \\
\text { support }\end{array}$ & $3 \sim 12$ & $8.42 \pm 1.92$ & $8.74 \pm 1.83$ & $7.31 \pm 1.81$ & -0.381 & $\begin{array}{l}\square \\
0.001\end{array}$ \\
\hline Total score & $12 \sim 66$ & $40.62 \pm 8.33$ & $42.74 \pm 7.41$ & $33.27 \pm 7.06$ & -0.578 & $\begin{array}{l}\square \\
0.001\end{array}$ \\
\hline
\end{tabular}

Table 8 Multivariate linear regression analysis of the influencing factors of anxiety in surgical nurses during COVID-19 $(N=3492)$ 


\begin{tabular}{|c|c|c|c|c|c|c|}
\hline Variables & $\beta$ & S.E. & $\begin{array}{l}\text { Standard } \\
\text { regression } \\
\text { coefficient }\end{array}$ & $t$-value & $\begin{array}{l}P \text { - } \\
\text { value }\end{array}$ & $95 \% \mathrm{Cl}$ \\
\hline constant & 66.089 & 0.983 & - & 67.248 & $\otimes 0.001$ & $64.162 \sim 68.015$ \\
\hline Fertility status & 1.469 & 0.489 & 0.076 & 3.004 & $0.003^{*}$ & $0.510 \sim 2.427$ \\
\hline Hospital & -0.611 & 0.117 & -0.068 & -5.212 & 0.001 * & $-0.841 \sim-0.381$ \\
\hline $\begin{array}{l}\text { Participation in care for } \\
\text { COVID } \\
-19\end{array}$ & 2.229 & 0.529 & 0.057 & 4.211 & 0.001 * & $1.191 \sim 3.267$ \\
\hline $\begin{array}{l}\text { Self-perception for } \\
\text { being infected with } \\
\text { COVID-19 }\end{array}$ & 1.146 & 0.180 & 0.094 & 6.369 & 0.001 * & $0.793 \sim 1.499$ \\
\hline Total score of SSRS & -0.623 & 0.015 & -0.576 & -40.540 & $\begin{array}{l}\square .001 * \\
0\end{array}$ & $-0.653 \sim-0.593$ \\
\hline
\end{tabular}

*mean $P \otimes 0.05$; The total score of anxiety was taken as the dependent variable and the variable with differences in table 8 as the independent variable.

Table 9 Multivariate linear regression analysis of the influencing factors of depression in surgical nurses during COVID-19 $(N=3492)$

\begin{tabular}{|c|c|c|c|c|c|c|}
\hline Items & $\beta$ & S.E. & $\begin{array}{l}\text { Standard } \\
\text { regression } \\
\text { coefficient }\end{array}$ & $t$-value & $\begin{array}{l}P \text { - } \\
\text { value }\end{array}$ & $95 \% \mathrm{Cl}$ \\
\hline constant & 66.024 & 1.094 & - & 60.347 & $\otimes 0.001$ & $63.879 \sim 68.169$ \\
\hline Divorce/ & -2.654 & 1.089 & -0.038 & -2.438 & $0.015^{\star}$ & $-4.788 \sim-0.520$ \\
\hline \multicolumn{7}{|l|}{ Widowed } \\
\hline Fertility status & 1.640 & 0.544 & 0.079 & 3.013 & $0.003^{*}$ & $0.573 \sim 2.707$ \\
\hline Hospital & -0.808 & 0.131 & -0.084 & -6.187 & $0.001 *$ & $-1.064 \sim-0.552$ \\
\hline $\begin{array}{l}\text { Participation in care for } \\
\text { COVID }\end{array}$ & 3.410 & 0.589 & 0.082 & 5.786 & 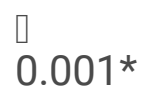 & $2.255 \sim 4.566$ \\
\hline \multicolumn{7}{|l|}{-19} \\
\hline $\begin{array}{l}\text { Self-perception for } \\
\text { being infected with } \\
\text { COVID-19 }\end{array}$ & 1.464 & 0.200 & 0.113 & 7.308 & $\begin{array}{l}0.001 * \\
0.01\end{array}$ & $1.071 \sim 1.857$ \\
\hline Total score of SSRS & -0.597 & 0.017 & -0.517 & -34.904 & $0.001 *$ & $-0.631 \sim-0.564$ \\
\hline
\end{tabular}


*mean $P \otimes 0.05$; The total score of depression was taken as the dependent variable and the variable with differences in table 8 as the independent variable. 